\title{
ERRATUM
}

\section{Climate Science: The other greenhouse effect}

Anna Armstrong

Nature Geoscience 1, 729 (2008); published online: 3 December 2008; corrected after print: 7 December 2008.

In the final paragraph of the above News \& Views piece, the rate of heating was erroneously given as being per year; it should have read per decade. This has been corrected on the HTML and PDF versions. 